\title{
Measures in the underground work method to determine the mathematical relations that predicts rock behaviour
}

\author{
S. Torno, J. Velasco, I. Diego, J. Toraño, M. Menéndez, \\ M. Gent \& J. Roldán \\ School of Mines, Oviedo University, Asturias, Spain
}

\begin{abstract}
The perforation parameter measure was introduced in geological prospecting and in the mining, petrol and gas industry, becoming an efficient tool allowing one to identify in detail and predict the geological and geomechanical characteristics while drilling is being carried out. The field measures and the calibration requirements of the tools and equipment used, which constitute the main obstacle in the prediction model establishment. Analogously, in underground excavations, the continuous knowledge of the rock mass, geological and geomechanical properties in front of the excavation wall during the operations, is of great importance in designing optimum, and also in the planning of the work carried out by this equipment and machinery. Through intense work measure campaigns, in the present work, the mathematical relations obtained in tunnel boring through a percussion perforation in blasting by a jumbo and a tunnel boring machine (TBM) are shown. Considering percussion perforation blasting for the models establishment or for the drilling parameters recorders (DPR) and tool adjustment, parameters such as uniaxial compressive strength, specific cut energy and destructive energy were used. Considering TBM and taking into account the high variable number that intervene in the tunnel boring process and also based on easily obtained parameters such as the already defined specific cut energy and the penetration index, we have reached a relation between the latter parameters and the rock mass rating index (RMR), which allows to adjust and subsequently predict the geological exploration from data which were previously carried out (were carried out previously to the project).
\end{abstract}

Keywords: tunnel boring machine, jumbo, mathematical relation, drilling parameter recorder. 


\section{Introduction}

The perforation parameter measurements are an efficient tool, allowing one to identify in detail and predict the geological and geomechanical characteristics while drilling is being carried out. The field measurements and the calibration requirements of the tools and equipment used, constitute the main obstacle to obtaining prediction models.



Figure 1: Jumbo used in percussion perforation.

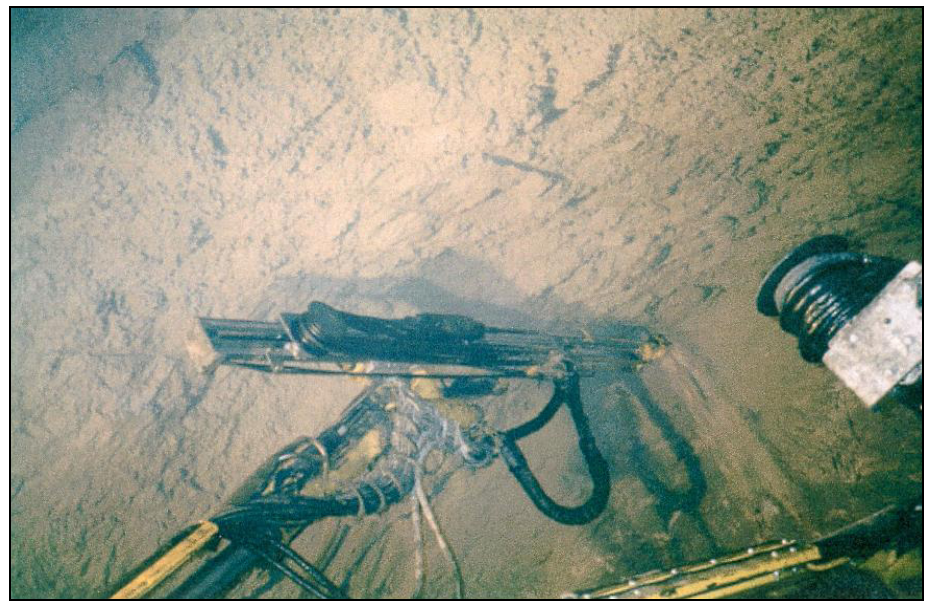

Figure 2: Jumbo machine detail.

In this research mathematical relations obtained from tunnel excavations, considering percussion perforation for blast by a jumbo (Fig. 1 and Fig. 2) and by a tunnel boring machine (TBM) (Fig. 3) are exposed. 
These mathematical relations are useful, in the percussion perforation case, to adjust the drilling parameter recorder (DPR) tools, and in the case of TBM to predict the rock mass geomechanical index (RMR).

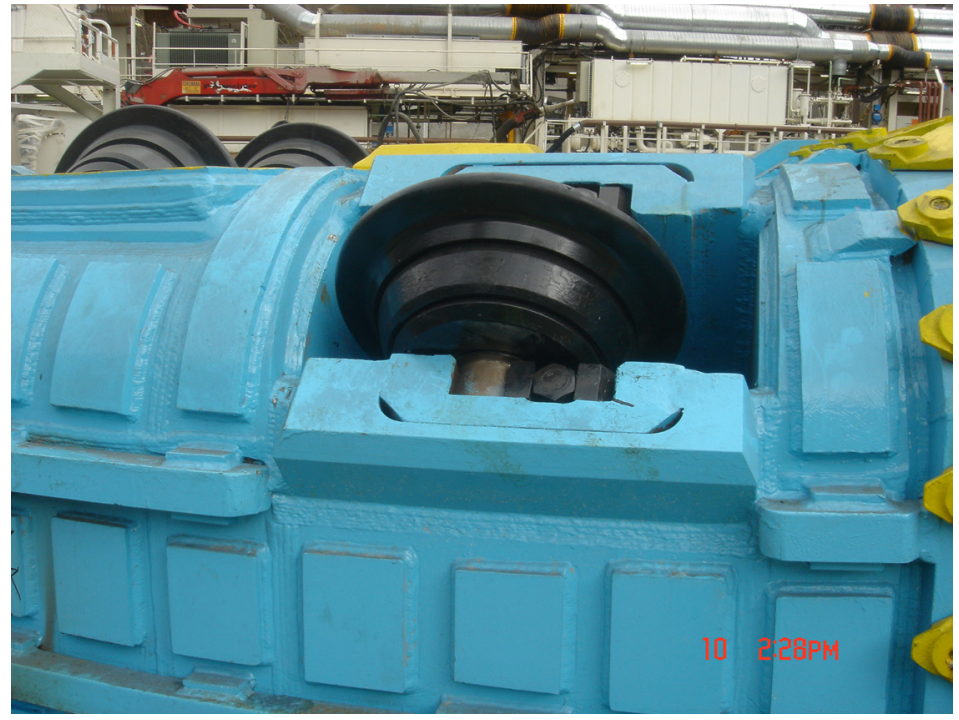

Figure 3: Disc Cutters of a tunnel boring machine.

Teale [1] introduced the specific energy concept as a necessary energy to excavate a unit rock volume and establish that it can be used as a mechanical property index of the rock mass. The correlation between the perforation parameters and the geological characteristics of rock mass in drill hole blasting in coal mining, was tested by Scoble et al. [2], who demonstrated, the relation between the penetration velocity variation, the rotation torque variation, the rotation velocity, the specific cut energy and the rock characteristics.

Schunnesson [3] established that the correlation between the obtained parameters from the perforation equipment monitoring and rock characteristics is not direct. The correlation may not occur when the perforation crosses broken rocks or in the case of no typical rock, also indicates, that external factors such as the tricone bit and the different string bar parts can influence the perforation parameters.

Turtola [4], through the geological data interpretation DPR obtained from rotation perforation in drill hole blasting, identifies the main rock types, based on the penetration velocity variation.

Likewise, Mozaffari [5] using DPR, together with an image analysis system, concluded that the penetration velocity measurement, the rotation torque and the specific energy while boring, provide relevant information about mechanic properties of rock mass.

We have come to the conclusion that DPR are systems in which the calibration 'in situ' together with other relations between variables are needed to 
obtain a good interpretation. In tunnel boring through TBM, it is difficult to predict the geomechanical conditions of rock mass in front of the machine owing to the observation difficulties and the large number of variables which control the excavation process. Geomechanical properties prediction methods of rock mass have been developed by machine operation parameters and geological geotechnical tunnel profiles (Rostami et al. [6] and Ozdemir [7]).

\section{Underground excavations. Mathematical models}

\subsection{Parameters in percussion perforation and TBM excavation}

Teale [1] indicated that the work process carried out in the rock breaking in each volume unit was related to the uniaxial compressive strength of that rock. Further research in this field has been carried out by Mellor [8], Reddish and Yasar [9], and Ersoy [10], and others.

Two types of specific energy can be distinguished in the rotation perforation, the one required to move a rock volume unit during rotation perforation $(S E v)$ Teale [1], and the energy to generate a new surface area $(S E a)$ Paithankar and Misra [11]. Specific energy is a cut mechanic efficiency index and can be considered as the sum both the pressure energy strength $e_{t}$ and the rotation energy $e_{r}$

$$
\begin{gathered}
\mathrm{e}_{\mathrm{t}}=\frac{F}{A} \mathrm{~kJ} / \mathrm{m}^{3} \\
\mathrm{e}_{\mathrm{r}}=\left(\frac{2 \pi}{A}\right)\left(\frac{N T}{V}\right) \mathrm{kJ} / \mathrm{m}^{3}
\end{gathered}
$$

where $F$ is the contact pressure $(\mathrm{kN}), A$ the excavated section $\left(\mathrm{m}^{2}\right), N$ the cutterhead rotation velocity (rpm) and $T$ the cutterhead rotation torque $(\mathrm{kN}-\mathrm{m})$.

If $p$ is named penetration per revolution, the previous equation becomes:

$$
\mathrm{SE}=\frac{F}{A}+\frac{2 \pi T}{A p} \mathrm{~kJ} / \mathrm{m}^{3}
$$

The $T / p$ relation is the necessary rotation torque to drill a rock length $p$ in one revolution. Therefore, it is considered as a useful specific energy indicator.

The $W z$ Specific Destruction Work $\left[\mathrm{kJ} / \mathrm{m}^{3}\right]$ is a required energy quantity measurement in the destruction, in new surface creation, or in rock cracks. This term allows the comparison between different rock materials. In Fig. 4, Young's modulus corresponds to the curve lineal slope from the starting point of the loading to the breaking point. The area under tension-deformation curve is the specific destruction work. Thuro [12] verified, by comparing the penetration velocities of different materials with their corresponding specific destruction work, in which the specific work is a parameter that presents a good correlation with the perforation velocity.

The relation between the uniaxial compressive strength and the specific cut energy in various rock types was analyzed by Reddish and Yasar [9]. The 
following equation, which relates the specific energy (SE) to the rock uniaxial compressive strength, was proposed:

$$
\mathrm{SE}[\mathrm{MJ} / \mathrm{m} 3]=9,927(\mathrm{UCS}[\mathrm{MPa}])-73,71
$$

In tunnel and mining gallery excavation by TBM, we emphasize the empiric prediction methods of the Norwegian Institute of Technology (NHT) Rostami et al. [6], the mathematical methods of the Colorado School of Mines (CSM) Ozdemir [7], the net penetration parameters $P$ (relation between the average advance $V$ and the rotation velocity $\omega$ ):

$$
P(\mathrm{~mm} / \mathrm{rpm})=\frac{V(\mathrm{~mm} / \mathrm{min})}{\omega(\mathrm{rpm})}
$$

and the penetration index Ip that represents the pushing that needs to be transmitted to a cutter $S c$ to penetrate $1 \mathrm{~mm}$ per revolution and it is also used for the indirect detection of the rock mass quality variations

$$
I p(k N / m m)=\frac{S c(k N)}{P(m m)}
$$

Based on our experiences in underground works and later as researchers in TBM tunnel execution we have contributed the mathematical relations which can help the setting up of the prediction methods and systems.

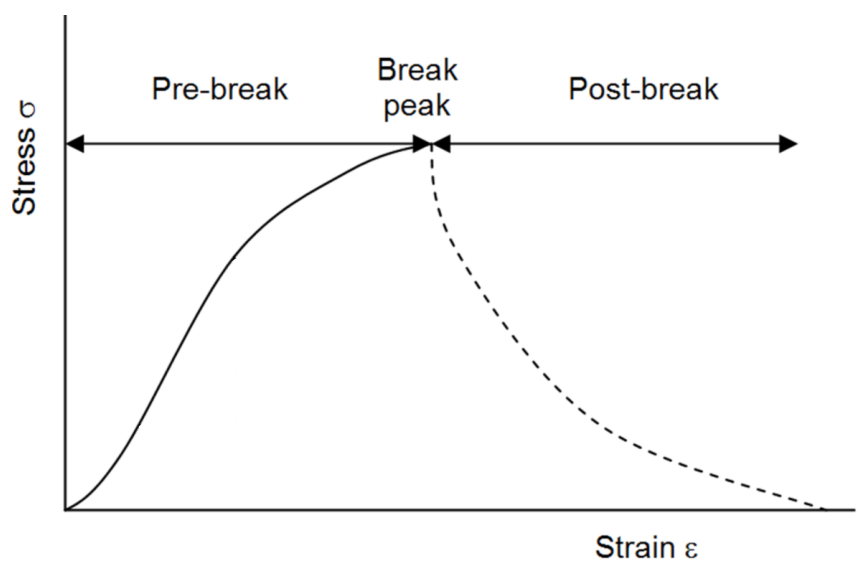

Figure 4: Wz, specific destruction work estimation, from tension deformation curve, of a rock sample under unconfined compression.

\subsection{Mathematical relations in percussion perforation}

During the excavation phase in Cabrejas tunnel in Guadarrama mountain chain (Spain), rock geomechanical characteristics in relation to boreability, which were different from the ones predicted in the project, were observed. For this reason, for example, it was sometimes necessary to change the predicted excavation system, turning from mechanical excavation to excavation by explosives. In order to avoid the latter and to establish a prediction model to get knowledge of 
the rock type in front of the excavation, a follow-up and rock resistance control during the excavation was carried out by normalized trials, such as the uniaxial compressive strength over the rock sample. In Fig. 5 the unconfined uniaxial compressive strength values carried out by the Franklin test, in a total of 460 trials are shown.

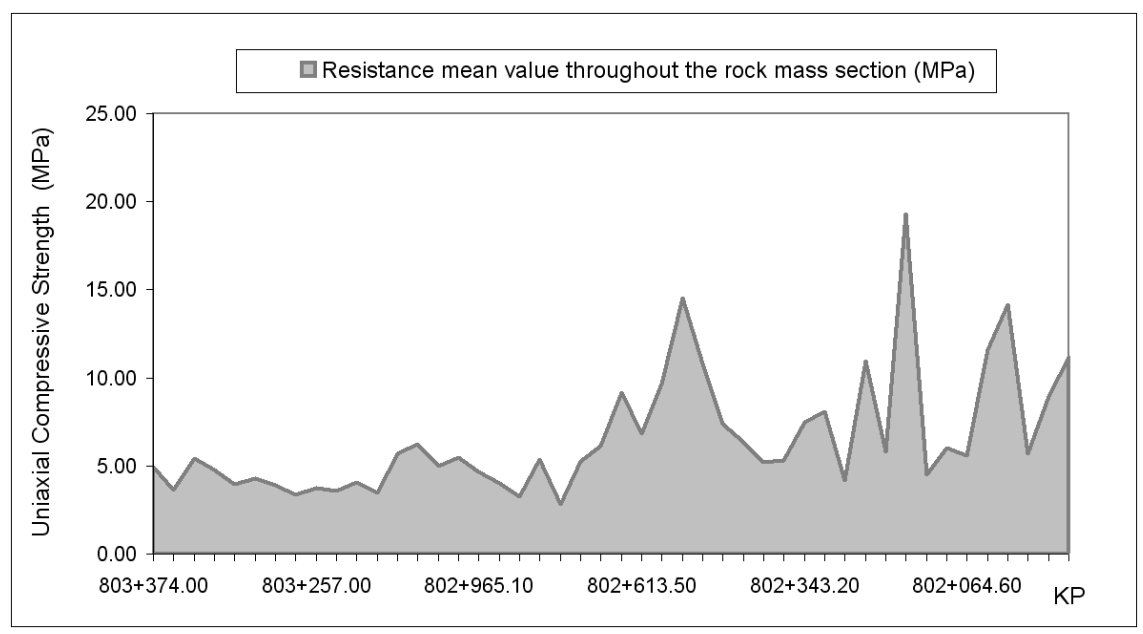

Figure 5: Unconfined uniaxial compressive strength by Franklin test.

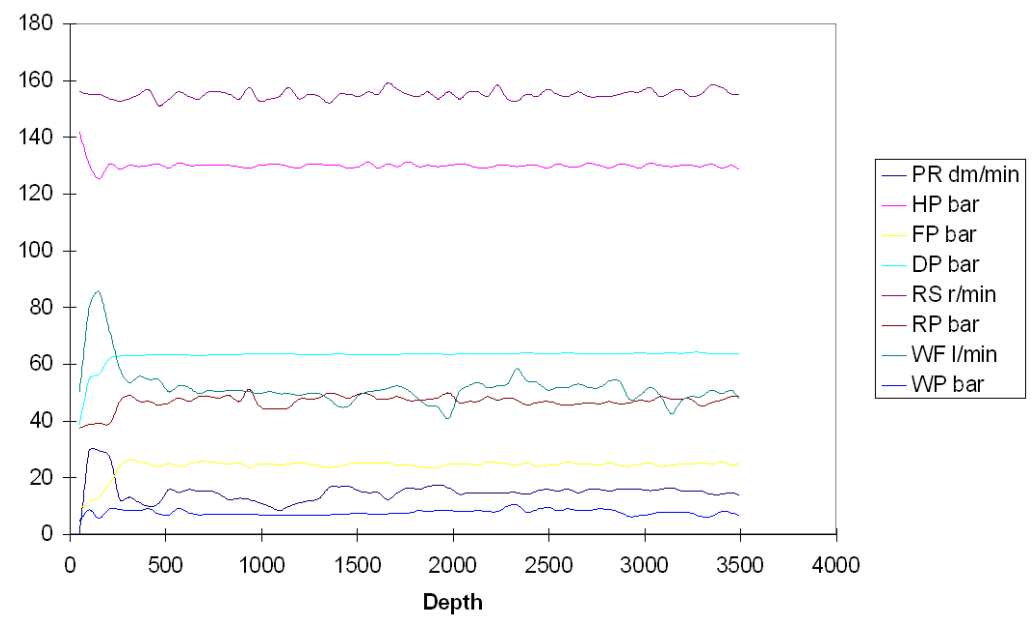

Figure 6: MWD (Measurement While Drilling) graphic registration outlet in a $4 \mathrm{~m}$ drill hole.

In this tunnel perforation, a jumbo equipped with a data register system (DPR), which registers (Fig. 6) the advancing depth (mm), the penetration velocity $(\mathrm{dm} / \mathrm{min})(\mathrm{PR})$, the percussion pressure $(\mathrm{HP})$, the advance pressure $(\mathrm{FP})$ 
and the damping pressure (bar) (DP), the rotation velocity (r.p.m.) (RS), the rotation pressure or force (bar) (RP) and both water flow (l/min) (WF) and pressure (bar) (WP), was used.

\subsection{Mathematical relations in TBM excavation}

Taking into account that in the tunnel boring machine case, the excavation is carried out by penetration, the specific rotation energy can be related to the RMR or Bieniawski index. In Fig. 7 the correlation between the two indicated parameters and the application of this correlation to new excavation fronts based on a campaign of 14,200 measurements in a tunnel executed in Guadarrama mountain chain, in Spain [13] are shown. It is excavated over both plutonic rocks and metamorphic rocks. The TBM machine has a 3,500 kW cutting power, a torque of $14,216 \mathrm{kNm}, 53$ simple discs and 4 double discs, all 17 inches in diameter.

Important relations between the specific rotation energy and the RMR geomechanical index (Fig. 8) were achieved from the data and the relations obtained.

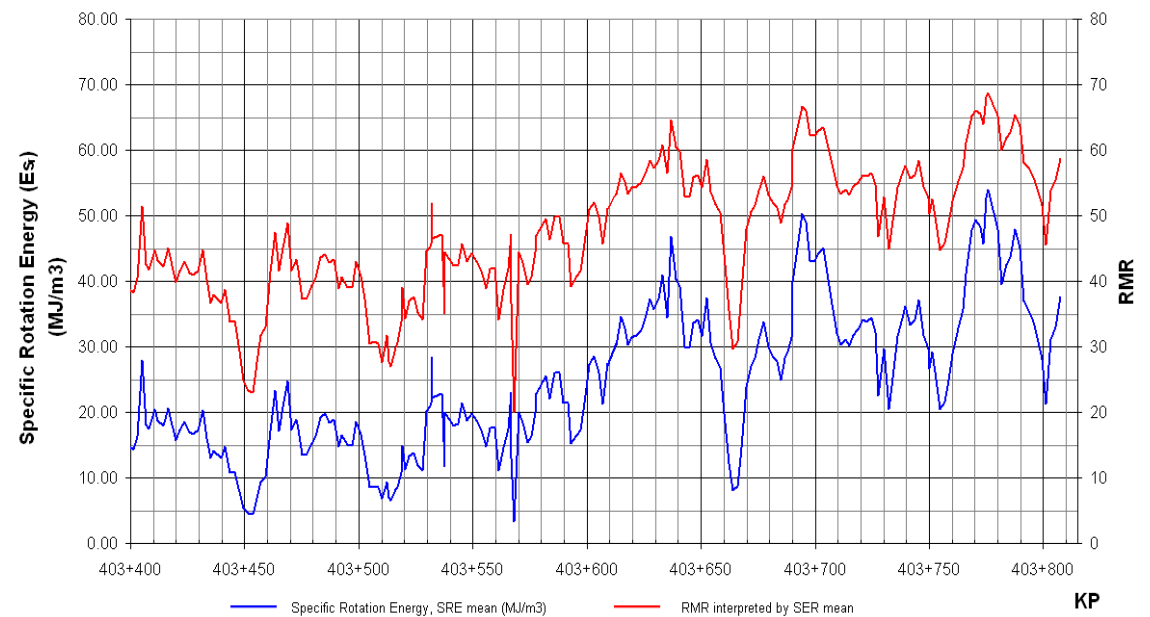

Figure 7: Relation between rotation energy and RMR.

\section{Conclusions}

A very important aspect in tunnel excavation is to predict the geological and geomechanical characteristics in the front of the tunnel, particularly in sections where the rock formation is expected to change considerably, allowing to take adequate measures before reaching conflictive rock mass formations.

The prediction models, which are the basis of the automatic systems to be implemented in the perforation equipment, can be estimated through traditional 


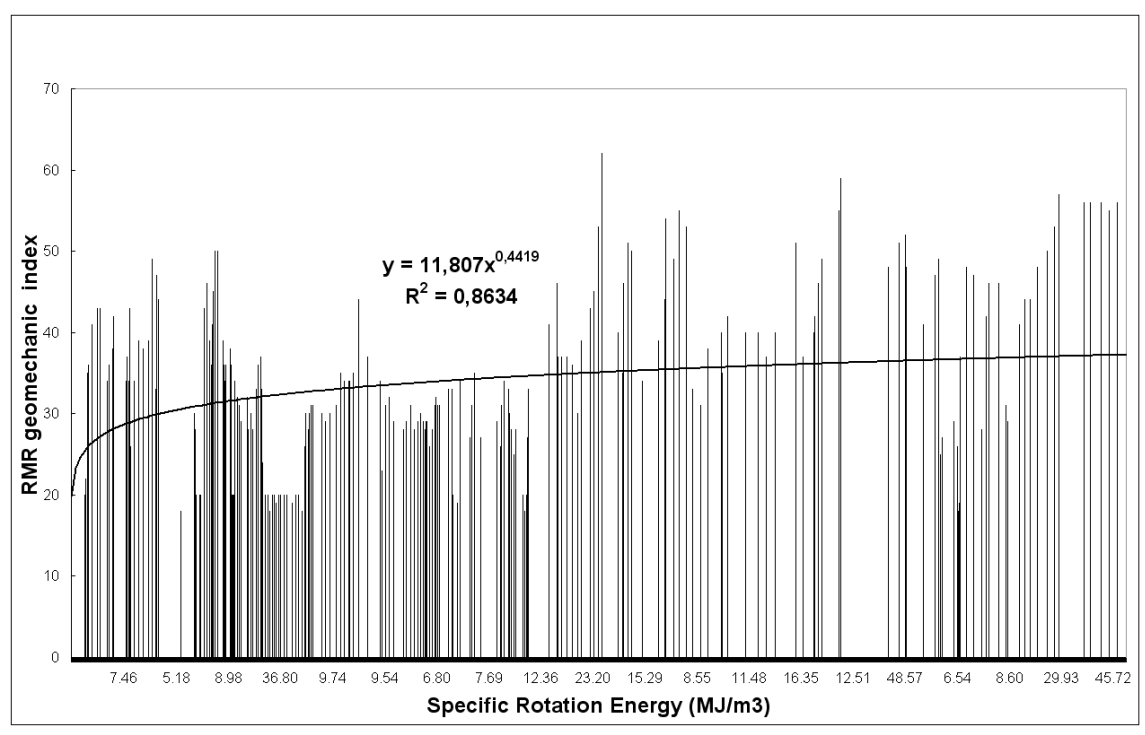

Figure 8: Relation between specific rotation energy and RMR index.

mathematics. In this methodology model adjustments through wide measurement campaigns are fundamental.

The perforability parameters recorded by the DPR tools and their adjustment by the corresponding measurement campaigns, allow to predict the rock mass behaviour and to optimize the perforation parameters. The Specific Cut Energy, the Uniaxial Compressive Strength and the Specific Destruction Energy, play an important role in this prediction methodology.

\section{References}

[1] Teale, R., The Concept of Specific Energy in Rock Drilling. Int. J. Rock Mech. Sci. Vol 2, pp. 57-73, 1965.

[2] Scoble, M.J., Peck, J., Hendricks, C., Correlation between Rotary Drill Performance parameters and Borehole Geophysical Logging. Mining Science and Technology, Vol. 8, pp. 301-312, 1989.

[3] Schunnesson, H., 1997. Drill process monitoring in percussive drilling for location of structural features, lithological boundaries and rock properties, and for drill productivity evaluation. Thesis (PhD). Lulea University of Technology (Sweden).

[4] Turtola, H., 2001. Utilization of Measurement While Drilling to Optimize Blasting in Large Open Pit Mining. Thesis (PhD). Lulea University of Technology (Sweden).

[5] Mozaffari, S., 2007. Measurement While Drilling System in Aitik Mine. Thesis (PhD). School of Applied Geosciences and Mining. Lulea University of Technology (Sweden). 
[6] Rostami, J., Ozdemir, L., Ilso, B., Comparison between CSM and TH Hard Rock TBM Performance Prediction Models. Proc. of Annual Technical Meeting of the Institute of Shaft Drilling Technology, Las Vegas, 1996.

[7] Ozdemir, L., 2003, CSM Computer Model for TBM Performance Prediction, Colorado School of Mines.

[8] Mellor, M., Normalization of specific energy. Int. J. Rock Mech. Sci. Vol. 9, pp. 661-663, 1972.

[9] Reddish, D.J., and Yasar, E., A new portable rock strength index tested based on specific energy of drilling. Int. J. Rock Mech. Sci. Vol. 33, n ${ }^{\circ} 5$, pp. 543-548, 1996.

[10] Ersoy, A., Automatic drilling control based on minimum drilling specific energy using PDC and WC bits. Mining Technology (Trans. Int. Min. Metal. A.), Vol. 112, pp 86-96, 2003.

[11] Paithankar, A.G., and Misra, G.B., Critical appraisal of the Protodyakonov index. Int. J. Rock Mech. Sci. Vol. 13, pp. 249-251, 1976.

[12] Thuro, K., Drillability prediction-geological influences in hard rock drilling blast tunnelling, Geol Rundsch Vol. 86, pp. 426-438, 1997.

[13] Tardáguila, J.L. Suarez, Metodología para el seguimiento y control del terreno en el interior de los túneles de Guadarrama. Ingeotúneles libro 12 (Capítulo 16), ed. Entorno Gráfico, pp. 329-360, 2007. 